\title{
Punched Card Records in Serials Acquisition
}

I MOST UNIVERSITY LIBRARIES the serials or serials and continuations; yet this is the account about which librarians know the least. Few know the amount of money expended-for specific departments, despite the fact that without that information it is impossible to do a thorough job of allocating book funds. It is a common practice to place periodical subscriptions with the periodical subscription agency on an "until forbidden basis," the selection of the agency having been determined by the quality of service given and the discount offered at the time the selection was made. Once a list of subscriptions is placed with an agent, a change is seldom made unless the service given becomes intolerable. This situation exists, not because librarians are uninterested in the best service at the minimum cost, but because of the labor involved in transferring the list to another agent. The same factor-labor costdeters the librarian from preparing an annual departmental analysis of the account which would help him in the equitable distribution of book funds.

Records essential in the acquisition of serials are the checking record-noting the receipt of successive issues, and the financial record-recording the subscription cost, agent, and expiration date. These records are either combined on a single form or are kept separately.

At the University of Texas Library separate checking and financial records have been and are maintained-the check- ing record in the form commonly found in libraries, but the financial record on punched cards, also known as tabulating cards. The punched card financial record was selected because of the desire for better control of serials acquisition procedures. Analysis of the account is not difficult since punched cards may be arranged, rearranged, duplicated, and tabulated mechanically. This mechanical facility makes possible the economical and accurate preparation of subscription bidding lists and renewal orders. Before the punched card was adopted for the financial record it was considered for the combined checking and financial record, but rejected, chiefly because of the space necessary to store the checking record dead file.

Three machines-an alphabetic printing punch, a sorter, and a tabulator (technically known as an alphabetic direct subtraction accounting machine)-are the minimum essential for the application described. With more extensive installations, combinations of machines may be substituted for the printing punch, resulting in greater economy of time because of the increased flexibility of procedure and higher operating speed of the specialized machines. For example, use of a sorter equipped with a multiple column selection device makes it possible to select all cards with a specific code in several columns without changing the sequence of the cards in either group. ${ }^{1}$

I For a description of equipment, see Baehne, George
Walter, ed. Practical Applications of the Punched Walter, ed. Practical Applications of the Punched Card Method in Colleges and Universities. New
York City, Columbia University Press, 1935, p. 10-19. 
Since total machine time for most libraries will not exceed fifty hours annually, the use of the punched card in serials acquisition is possible only if the necessary equipment is available for library use. In many of the larger colleges and universities applications of the punched card method are found in the registrar's office or the business office, and the equipment will usually be available for use by others.

\section{Procedure}

Information punched in the tabulating card will vary according to the results wanted. Before determining the code, careful consideration should be given to the utilization of the records to be produced. If unnecessary work is to be avoided, no pertinent information should be omitted in the initial preparation of the cards. For the records prepared in the University of Texas Library the following information is punched on the card:

I. Title. The title is abbreviated to fortythree letters and spaces because of the printing limitations of the tabulator

2. Expiration date or volume number. The expiration date is preferable if the subscription can be so placed. Expiration date cards can be reproduced automatically for the following year, while volume numbers must be punched manually in the next year's card

3. Department benefited

4. Account charged. Departmental or general library account

5. Source. The dealer employed or other source

6. Country of publication

7. Location in the library (periodical reading room, chemistry library, etc.)

After the cards have been punched, they are mechanically arranged in alphabetical order; and, as invoices are paid, subscription costs and binding costs are posted on the cards in handwriting. At the close of the fiscal year the posted costs are punched in each card.
After the cards have once been prepared, they can be automatically reproduced for the next year's record, at a rate of from eighty to one hundred cards per minute.

\section{Analysis of the Account}

As a brake on departmental enthusiasm, it has been the practice in this library to charge the first three years' subscription costs of a new serial to the book allocation of the department requesting the title. For the same reason the subscription costs of added copies of serials and the subscription costs of continuations are charged, in perpetuity, to the departmental book allocations. In other words, the library's general serials and continuations account assumes responsibility for only one copy of a serial in order to assure a complete file. Additional copies are assumed to serve a specific departmental rather than a general need. The "three-year rule" is assumed to minimize the overloading of library income with dubious subscriptions. A continuation is thought of as an incomplete separate issued in parts. Because it is regarded as a separate the cost is charged to the departmental book allocation.

Prior to the adoption of the punched card record, invoices covering serials and continuations were analyzed and costs charged directly to the departmental accounts. As a rule postings to several accounts were necessary to distribute the costs of titles on a single invoice. Now only the total of the invoice, a charge to the serials and continuation account, is posted in the ledger at the time the invoice is paid. At the end of the fiscal year, after the serials and continuations account has been analyzed, costs are distributed to the departmental accounts and the library's general serials and continuations account. After subscription costs and binding costs have been punched in the cards at the close of the fiscal year, the cards are mechanically 
sorted by department and account and then tabulated. From the totals thus obtained an analysis sheet for the serials and continuations account is readily prepared. On the analysis sheet, column $I$ shows the cost of subscriptions placed during the year; column 2, the cost of titles received for the second year; column 3 , the cost of titles received for the third year; column 4, the cost of added copies and continuations; and column 5, the total of columns I-4. In column 6 is found the cost of serials of more than three years' standing, carried on the general serials and continuations account. Column 7 , the total of columns 5 and 6 , gives the cost of all serials and continuations received by the department.

During the year, as notices of suspensions are received or decisions to cancel are made, the information is punched in the cards. After the first seven columns of the analysis sheet have been completed, but before duplicating the cards for the following year, canceled and suspended titles are removed by the sorter. These cards are tabulated to obtain the cost of discontinued serials and continuations, which is placed in column 8 of the analysis sheet. With these costs known, a more accurate budget can be made for the following year.

\section{Departmental Lists}

At the beginning of the fiscal year, and prior to the placement of renewal subscriptions, a list of currently received serials and continuations initially acquired at the department's request is submitted to each department. Subscription cost, binding cost, and expiration are shown for each title listed. Attached to each departmental list is a letter to the- departmental chairman asking that he and the faculty of the department examine the list, place orders for any new titles wanted, and suggest cancellation of any serials which are no longer of value to the department. This annual re- view of serials subscriptions prevents the accumulation of deadwood and offers an occasion for adding hitherto overlooked titles.

\section{Bidding Lists}

Without punched cards the task of preparing to take bids on periodical subscriptions is a lengthy one. A combination of good records and an accurate worker is necessary. Errors may result in duplication or missed numbers. Consequently, libraries frequently place their periodical subscriptions and renewals with the same agent year after year because of the assumption that any increased discount received would not compensate for the labor cost and inconvenience involved. Employment of punched cards greatly reduces the costs of obtaining bids and, when advantageous, of changing agents. The operations necessary after the cards have been reproduced are similar to those required for producing the departmental lists; the cards are mechanically sorted and the desired information, i.e., title and expiration volume number, is printed by the tabulator. Quotations submitted by agents often give notice of suspensions and other information about titles in the list. After necessary revisions have been made in the cards, the order is printed by the tabulator from the same punched cards.

Additional values are derived from other uses of the basic data on the punched cards. An annual record of all serial and continuation acquisitions, showing the volume, subscription cost, binding cost, source, and departmental assignment for each title, is prepared. Copies of this list in the offices of the library's administrators are useful in answering many of the questions concerning serials without the necessity of referring to the serials unit for information.

In the University of Texas Library there are twenty branch libraries, special collec- 
tions, and reading rooms in which serials are located. To facilitate the use of serials by the clientele an alphabetical location list of all currently received serials and continuations is provided for each circulating unit. To produce the required number of copies, the cards must be put through the tabulator several times, but the cost is not excessive since the listing speed of the tabulator is eighty lines per minute and four or five copies may be made in each run.

Upon occasion it may be useful to know which serials received by the library, are published in specified countries or from a given dealer. A printed list of either can be prepared in a few hours time. The utility of this feature was demonstrated by the ease with which lists of serial subscriptions from Germany and German-occupied nations were prepared at the time the Joint Committee on Importations announced its plan for securing serials from those nations. These lists- simplified the task of selecting titles to be requested for allotment by the joint committee. More frequently useful are lists arranged by dealer to facilitate the shifting of subscriptions from dealers giving unsatisfactory service or discounts.

\section{Summary}

The punched card application which has been described was developed to produce specific results for the needs of the Univer- sity of Texas Library. Requirements of other libraries will vary, but the flexibility of the punched card method permits an application tailored to individual needs.

Assuming that the necessary equipment is available for use by the library, the decision to adopt or not to adopt the punched card as a financial record should be determined by the products wanted. If employed solely as a financial record, the application might not repay the library for the labor entailed in the initial preparation of the record. But if it is also utilized for some of the other purposes mentioned-the analysis of the account, the preparation of bidding lists and renewal orders, and the printing of a union list of serials and continuations-the economies of the punched card are readily apparent. Of equal or greater importance to the librarian is the increased control of the serials and continuations account made possible by the various analyses. With the departmental lists and the advice of the departments concerned, useless titles may be eliminated and desirable titles added. The departmental lists also enable the librarian to distribute serials costs to the departments, if desirable, or to determine the extent to which the departments benefit by expenditures from the general account. The superiority of the method lies in the economy and accuracy with which lists and analyses can be made. 